\title{
Strength Control Factors of Chlorite Schist under Schistose Structure
}

\author{
Siquan Yan ${ }^{1}$, Qiankuan Wang ${ }^{2}$, Hongfei Wang ${ }^{1}$, Shili Qiu ${ }^{2 *}$, Zhiquan Zeng ${ }^{3}$, Yue Fang ${ }^{2,4}$ \\ ${ }^{1}$ Yellow River Engineering Consulting Co., Ltd., Zhengzhou 450000, China \\ ${ }^{2}$ Institute of Rock and Soil Mechanics, Chinese Academy of Sciences, Wuhan 430071, China \\ ${ }^{3}$ Huadong Engineering Corporation Limited, PowerChina, Hanghzou 31001, China \\ ${ }^{4}$ School of Civil Engineering and Architecture, Anhui University of Science and Technology, Huainan 232000, China
}

Corresponding Author Email: slqiu@whrsm.ac.cn

https://doi.org/10.18280/ijdne.150503

Received: 5 May 2020

Accepted: 19 August 2020

\section{Keywords:}

rock mechanics, chlorite schist, bedding angle, moisture condition, weathering state

\begin{abstract}
In tunnel engineering, it is important to understand the influence of schistose structure on the failure strength of chlorite schist. To explore the strength control factors of chlorite schist, this paper firstly analyzes the mineral composition and meso structure of chlorite schist of different weathering states. The results show that the mineral composition of chlorite schist is changed during the weathering process, and that chlorite is an anisotropic rock mass. Next, a series of uniaxial compressive tests were conducted on chlorite schist samples with different bedding angles (the angle between bedding plane and loading direction; $\theta=0^{\circ}, 15^{\circ}, 30^{\circ}, 45^{\circ}, 60^{\circ}, 75^{\circ}$, and $90^{\circ}$ ), moisture conditions (dry and saturated), and weathering states (strongly weathered and weakly weathered). Based on the test data, the authors discussed the change laws of the rock strength with bedding angle, weathering state, and moisture condition. The main results are as follows: Chlorite schist is a low-anisotropy rock mass, whose compressive strength exhibited a V-shaped trend with the growing bedding angle; the schistose structure is the internal cause of the deformation and the anisotropic or transversely isotropic strength of the schist; the schistose structure is reshaped and further damaged by external factors (e.g. water softening and weathering effects) in engineering. The research findings help to improve the rock stability and support design in tunnel engineering.
\end{abstract}

\section{INTRODUCTION}

Among metamorphic rocks, schistose rocks are known for their significant anisotropy, which manifests as the obvious variation in strength parameters with the bedding angle (the angle between the bedding plane and loading direction) [1]. Chlorite schist, a typical metamorphic rock with schistose structure, features low strength and large deformation in engineering. In the engineering environment, chlorite schist is susceptible to expansion, disintegration, dissolution, and weathering [2].

The failure modes of schistose rocks fall into three categories [3, 4]: the shear failure mode, where the main crack develops along the bedding angle; the tensile failure mode, where the main crack develops vertically along the loading direction; the mixed failure mode, where the shear plane suffers both shear failure and tensile failure, while the rock away from the shear plane suffers from tensile failure.

In engineering, the primary failures of schistose metamorphic rocks include landslides and collapses in the rainy season, which occur in the form of consequent or insequent landslides [5]. When a shallow tunnel encounters the formation of schistose metamorphic rocks, the surrounding rock often suffers from structural collapse, and compressional deformation, inducing surface settlement [6]. These failures severely threaten construction safety and project progress. Take the Northern Hubei Water Resources Allocation Project for example. During the construction of the Tangxian-
Shangshi (T-S) tunnel, largescale landslide, roof fall, and even thorough collapse took place in the chlorite schist segment. Therefore, it is of great importance to analyze the influence of schistose structure on the deformation strength of metamorphic rocks in lab tests.

Many scholars have explored how schistose structure affects the physical and mechanical properties of rocks through lab tests. For instance, Read et al. [7] conducted indoor uniaxial compression tests to study the elastic modulus, Poisson's ratio, and other strength parameters of schist, and established a transversely isotropic constitutive model of the rock. Through uniaxial compressive tests, Li et al. [8] observed the obvious transverse isotropy of slate, and found that the bedding angle greatly affects the compressive strength. Liu et al. [9] performed uniaxial compression and indirect tensile tests on disc samples, pointing out the obvious anisotropy of chlorite schist. Zhou et al. [10] carried out uniaxial and ordinary triaxial tests with $\mathrm{NaCl}$ solution and distilled water, respectively, and learned that chlorite schist softens in contact with water. Liu et al. [11] conducted uniaxial and triaxial compression tests on chlorite schist, revealing the strong deformability and water softening effect of the rock. Based on indoor splitting tests, Liu et al. [12] examined the transverse isotropy of quartz mica schist, and summed up the change laws of tensile strength, deformation modulus, and Poisson's ratio. $\mathrm{Wu}[13]$ tested the anisotropy of mica quartz schist in mineral composition and microstructure, and calculated the rock weathering coefficient. Through triaxial 
tests with different bedding angles, Sun et al. [14] discovered the significant impact of water on the elastic modulus, internal friction angle, and cohesive force of quartz mica schist.

Based on engineering behaviors, the above studies mainly provide qualitative results through theoretical and empirical analyses. These results are insufficient to satisfy the tunneling requirements under complex geological conditions. Despite these studies, the following issues remain unclear: the influence of external factors on the mechanical properties of chlorite schist, the influence of physical and mechanical anisotropy on tunnel excavation, the water softening effect and the law of anisotropic softening, and the law of damage evolution under schistose structure.

Therefore, this paper carries out indoor tests on the compressive strength of chlorite schist, and identifies the key factors controlling the strength of chlorite schist, namely, schistose structure, weathering state, and moisture condition, revealing how the macro and meso features of schistose structure control the strength of the rock. The research results guide the scientific support and safe construction of tunnels.

\section{TEST CONDITIONS AND TEST PLAN}

\subsection{Lithological conditions and sample preparation}

(1) Sample acquisition

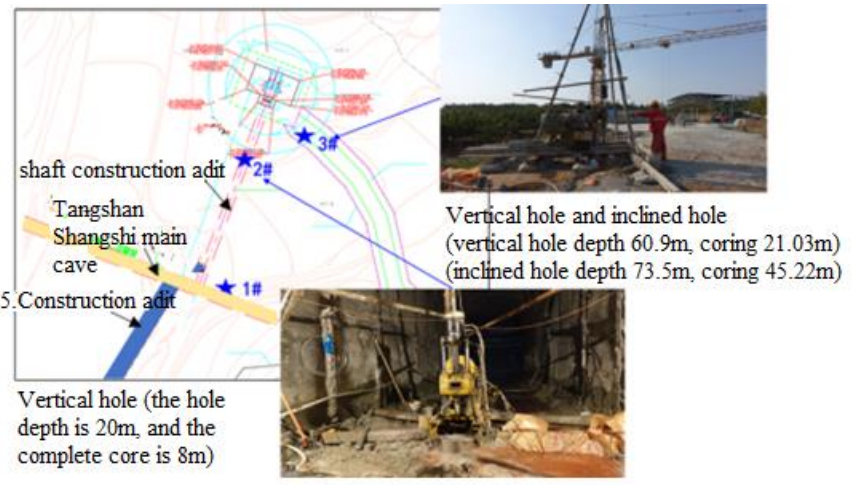

Note: The five-pointed stars are the locations of the drill holes.

Figure 1. The drilling and coring positions

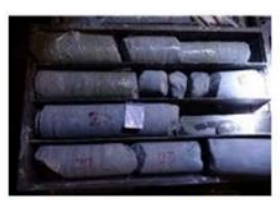

(a) Vertical hole core of $\mathrm{N}_{0.5}$ branch tunnel

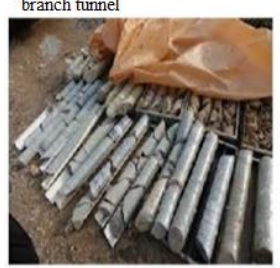

(d) All cores are sealed with tape

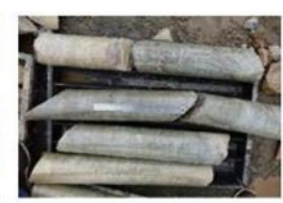

(b) Vertical core beside shaft

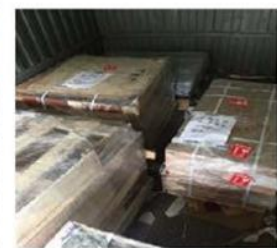
(e) All transportation is packed in wooden boxes, and the cores are
separated by cotton wadding and old clothes between each layer of cor
Figure 2. The cores and packages

The rock samples are weakly weathered chlorite schists with typical schistose structure and water softening effect. The mineral components mainly include hornblende, chlorite, muscovite, and quartz. The samples were cored in the main tunnel of the T-S tunnel, the Northern Hubei Water Resources Allocation Project, and in the diversion tunnel of Huangzangsi Key Water Control Project. Most cores are from the weakly weathered schist formation, with a coring recovery rate of $40 \%$. Starting from the surface, the drill hole $3 \#$ penetrated through the overburden and fully-weathered schist formation, and reached the weakly weathered schist formation, with a coring recovery rate of $27 \%$. The drilling and coring positions are shown in Figure 1, and the cores and packages are illustrated in Figure 2.

(2) Sample processing and preparation

To facilitate the study on the influence of schistose structure on the deformation and failure mechanism, the obtained cores were cut into $37.5 \mathrm{~mm} \times 75 \mathrm{~mm}$ samples (scale: $1: 2$ ), in the light of the core diameters and bedding angles $\theta$. As shown in Figure 3 , the bedding angles $\theta$ of the processed samples were $0^{\circ}, 15^{\circ}, 30^{\circ}, 45^{\circ}, 60^{\circ}, 75^{\circ}$, and $90^{\circ}$, respectively. The mean density of the samples stood at $2,980 \mathrm{~kg} / \mathrm{m}^{3}$. The flatness difference between upper and lower ends fell within $\pm 0.3 \mathrm{~mm}$, and surface flatness was controlled as $\pm 0.05 \mathrm{~mm}$. Both ends of each sample were kept perpendicular to the axis, with an allowable deviation of $\pm 0.25^{\circ}$. The processing precision was determined according to the Specifications for Rock Tests in Water Conservancy and Hydroelectric Engineering (SL2642001).

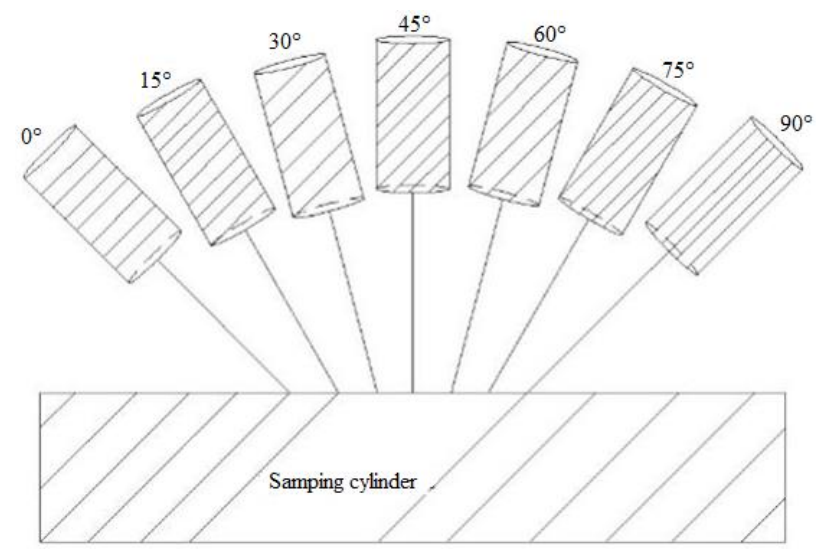

(a) Directional coring of cylindrical samples

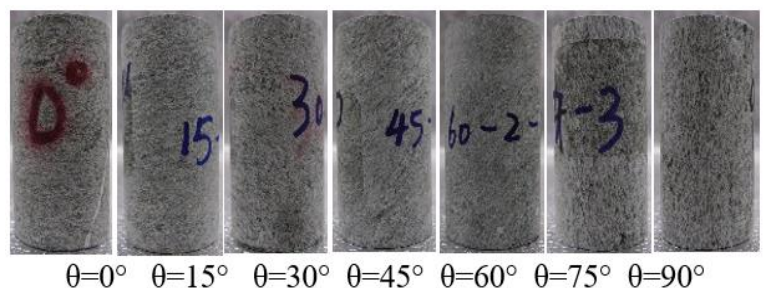

(b) Cylindrical samples

Figure 3. The processed samples

\subsection{Mineral composition of chlorite schist}

Chlorite minerals concentrate along the dominant development direction, and agglomerate into a heterogeneous layer, forming interbedding with quartz, mica, and albite minerals. This special distribution of minerals forms the macro schistose structure of chlorite schist. The macro mechanical behaviors of the rock are controlled by the meso features.

To facilitate the analysis on the macro schistose structure of chlorite schist, the meso physical structure and mineral particle distribution of the rock were explored through mineral composition analysis on the strongly weathered samples (T1- 
3) and weakly weathered samples (T5-7) of the chlorite schists collected from the Northern Hubei Water Resources Allocation Project, with the aid of X-ray diffractometry (XRD).

Table 1 compares the mineral compositions of the six samples obtained by XRD. It can be seen that the strongly weathered samples mainly encompassed albite (30\%), quartz $(20 \%)$, and muscovite (49\%), plus a small amount of zeolite; the weakly weathered samples mainly consisted of clinochlorite $(50 \%)$, actinolite $(18 \%)$, muscovite $(15 \%)$, and albite $(15 \%)$, plus a small amount of dolomite.

It can be inferred from the results that strongly weathered chlorite schist contains fewer clinochlorite, actinolite, and muscovite, but more $\mathrm{SiO}_{2}$ and $\mathrm{Fe}$ than weakly weathered chlorite schist. The mesoscale reason lies in the oxidation reaction between chlorite schist and water. When the undisturbed rock is eroded by water, its clinochlorite, actinolite, and muscovite are hydrolyzed into soluble salts and insoluble $\mathrm{SiO}_{2}$ and $\mathrm{Fe}$. The water erosion alters the mineral composition, and increases the pores in the rock, reducing its mechanical strength.

Table 1. The mineral compositions of chlorite schist

\begin{tabular}{ccccccc}
\hline Content \% & TI & T2 & T3 & T5 & T6 & T7 \\
\hline Albite & 40.26 & 29.36 & 31.6 & 23.85 & 17.57 & 14.77 \\
Quartz & 13.97 & 20.28 & 17.28 & & & \\
Zeolite & 0.14 & 0.15 & 0.18 & & & \\
Muscovite & 45.63 & 50.21 & 50.16 & 16.44 & 13.67 & 14.58 \\
Dolomite & & & 0.79 & 3.37 & 1.51 & 1.94 \\
Clinochlorite & & & & 37.12 & 46.47 & 47.48 \\
Actinolite & & & & 19.22 & 20.78 & 21.23 \\
\hline
\end{tabular}

\subsection{Meso features of chlorite schist}

From the samples, it is learned that chlorite has a flaky meso structure. In the plane of the schistose structure, the mineral molecules of chlorite schist are evenly arranged, and superimposed into chlorite schist.

To disclose the meso anisotropy of chlorite schist, Figure 4 provides the measured and simulated results on strongly and weakly weathered samples obtained through polarized light microscopy (PLM).

As shown in Figure 4(a), the weakly weathered sample had a dense internal structure. The different layers were arranged irregularly, except in a few local areas. The boundaries between the layers were rather vague. Among the main components, quartz existed as colorless granulates, obeying directional mosaic distribution; hornblende existed as blastoporphyritic columns, and followed directional distribution in the shape of eyeballs; chlorite existed as flakes, mostly distributed as directional aggregates; muscovite also existed as flakes, and satisfied continuous and directional distribution in the shape of scales.

As shown in Figure 4(b), the strongly weathered sample contained numerous pores and micro-cracks. The microcracks extended along the edge of the sample. The macro distributions of minerals exhibited obvious directionality. Specifically, quartz existed as semi-idiomorphic to xenotopic crystals, and satisfied continuous and directional distribution in the form of colorless small yet visible inclusions; muscovite existed as flakes, obeying continuous and directional distribution; garnet existed as numerous small, pink homogeneous bodies.

From the meso mechanics, chlorite schist can be regarded as an anisotropic material superimposed from isotropic sheets of minerals.

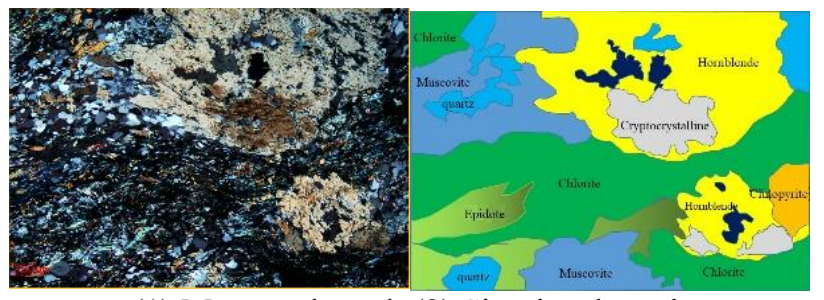

(1) Measured result (2) Simulated result

(a) PLM images of weakly weathered sample

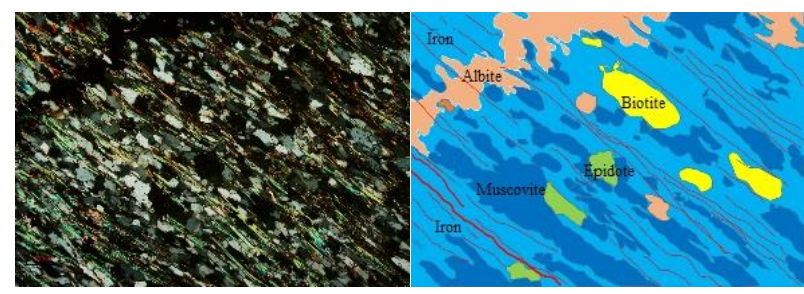

(1) Measured result (2) Simulated result

(b) PLM images of strongly weathered sample

Figure 4. The PLM images of chlorite schist

\section{TEST PLANS AND PROCEDURE}

\subsection{Test plans}

Four test plans were implemented, namely: (1) the test plan for anisotropy; (2) the test plan for the effect of bedding angle; (3) the test plan for water softening effect; (4) the test plan for weathering effect. The four plans give full consideration to the coupling between anisotropy, bedding angle, water softening effect, and weathering effect, and thoroughly disclose how the four factors influence the strength of chlorite schist. The details of the test plans are shown in Table 2.

Table 2. The test plans

\begin{tabular}{|c|c|c|c|c|c|c|}
\hline \multirow{3}{*}{$\begin{array}{l}\text { Bedding } \\
\text { angle }\end{array}$} & \multicolumn{2}{|c|}{ Sample size } & \multicolumn{4}{|c|}{ Number of cylindrical samples for uniaxial compression } \\
\hline & \multirow{2}{*}{$\begin{array}{c}\text { Diameter } \\
\mathbf{m m}\end{array}$} & \multirow{2}{*}{$\begin{array}{c}\text { Height } \\
\text { mm }\end{array}$} & \multicolumn{2}{|c|}{ Weakly weathered } & \multicolumn{2}{|c|}{ Strongly weathered } \\
\hline & & & Dry & Saturated & Dry & Saturated \\
\hline $0^{\circ}$ & & & 5 & 5 & 4 & 5 \\
\hline $15^{\circ}$ & & & 5 & 5 & 5 & 5 \\
\hline $30^{\circ}$ & & & 5 & 5 & 5 & 5 \\
\hline $45^{\circ}$ & 37.5 & 75 & 5 & 5 & 2 & 4 \\
\hline $60^{\circ}$ & & & 5 & 5 & 5 & 3 \\
\hline $75^{\circ}$ & & & 4 & 3 & 5 & 5 \\
\hline $90^{\circ}$ & & & 5 & 5 & 5 & 5 \\
\hline
\end{tabular}




\subsection{Test procedure}

The load was applied by the MTS815.04 electro-hydraulic servo loading test machine at the Institute of Rock and Soil Mechanics, Chinese Academy of Sciences. The maximum vertical output is $4,600.0 \mathrm{kN}$, the maximum axial tensile load is $2,300 \mathrm{kN}$, and the maximum confining pressure is $140 \mathrm{MPa}$. The sensor arrangement is shown in Figure 5.

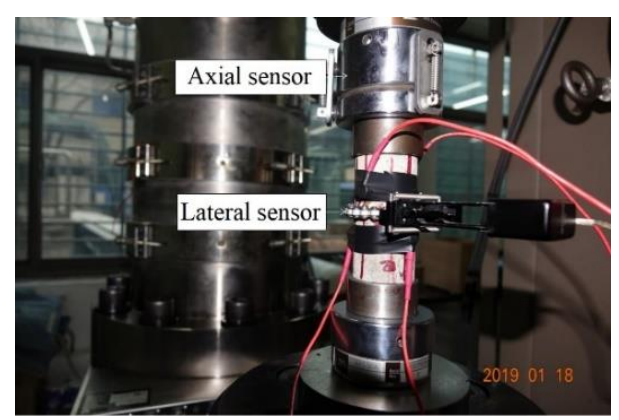

Figure 5. The sensor arrangement

Uniaxial compression tests were conducted to compare the strengths, elastic moduli, and Poisson's ratios of chlorite schist samples with different bedding angles, weathering states (strongly weathered or weakly weathered), and moisture conditions (saturated or dry). Based on the measured data, the authors summarized how the mechanical parameters of chlorite schist is affected by anisotropy, bedding angle, water softening effect, and weathering effect.

During the tests on bedding angle and weathering state, all the samples were in natural dry state. The saturated samples were prepared through $24 \mathrm{~h}$ drying and $48 \mathrm{~h}$ immersion in water in a vacuum tank at room temperature. According to the Test Methods of Rock for Highway Engineering (JTG E41-2005), the samples after $48 \mathrm{~h}$ immersion has a moisture content as high as $94 \%$, and will absorb very little water. Therefore, the saturated samples can fully demonstrate the water absorption features of the rock.

\section{ANALYSIS ON CONTROL MECHANISM}

\subsection{Influence of anisotropy}

The samples for uniaxial compression tests were not of standard size. Considering various conditions, the uniaxial compressive strength $\sigma_{C 50}$ of each $50 \mathrm{~mm} \times 100 \mathrm{~mm}$ cylindrical sample was converted by the formula of Brown and Hoek [15] into the uniaxial compressive strength $\sigma_{C}$ of the chlorite schist of the actual size: $\sigma_{c}=\sigma_{c 50}\left(\frac{50}{D}\right)^{0.18}$, where $\mathrm{D}$ is the diameter of the cylindrical sample. Figure 6 shows the strengths obtained through conversion.

From the above results, it can be seen that the strength of chlorite schist is significantly anisotropic with the change in bedding angle. The anisotropy of chlorite schist can be quantified by [16]:

$$
K_{1}=\frac{\sigma_{90}}{\sigma_{\min }}
$$

where, $\sigma_{90}$ is the uniaxial compressive strength at the bedding angle of $90^{\circ} ; \sigma_{\min }$ is the minimum uniaxial compressive strength as the bedding angle changes between 0 and $90^{\circ}$.

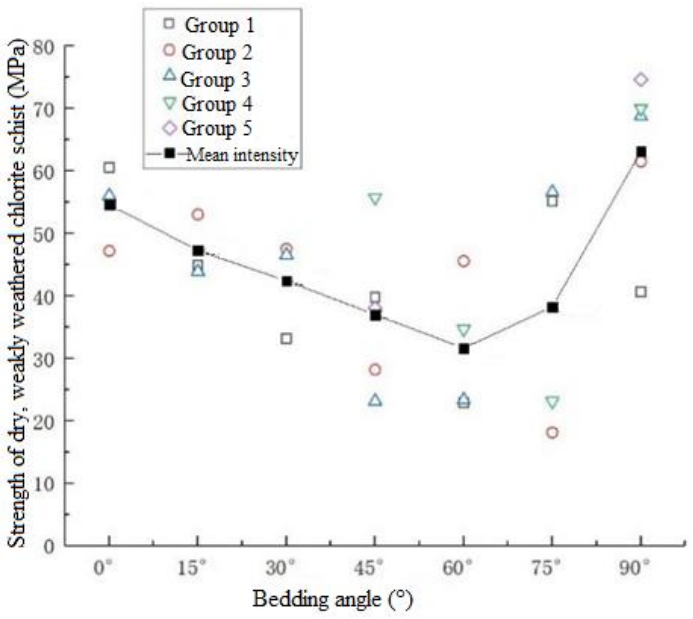

Figure 6. Strength parameters of weak weathering natural state of chlorite schist

As shown in Figure 3, the anisotropy of the uniaxial compressive strength increased with the bedding angle. The reason is that, during the loading, the degree of cracking is suppressed by the bedding angle, which acts on the pores and micro-cracks. The anisotropy of the compressive strength is thereby enhanced.

The mean anisotropy $K_{1}$ of the uniaxial compressive strength of chlorite schist samples was obtained as 1.94. Referring to the Singh's anisotropy ratio [17], the chlorite schists from the Northern Hubei Water Resources Allocation Project and Huangzangsi Key Water Control Project are both low-anisotropy rock masses.

According to the generalized Hooke's law [17], the transversely isotropic elastic constitutive equation has five independent elastic constants. The details of these constants are omitted due to the limited space. Table 4 records the calculated values of the transverse anisotropy parameters, where $\mathrm{E}$ is the elastic modulus parallel to the isotropic plane, $E^{\prime}$ is the elastic modulus perpendicular to the isotropic plane, $v$ is the Poisson's ratio parallel to the isotropic plane, $v^{\prime}$ is the Poisson's ratio perpendicular to the isotropic plane, and $G=E / 2(1+v)$ is the shear modulus perpendicular to the isotropic plane.

Table 3. The anisotropies at different bedding angles

\begin{tabular}{cccccccc}
\hline Anisotropy & $\mathbf{0}^{\circ}$ & $\mathbf{1 5}^{\circ}$ & $\mathbf{3 0}^{\circ}$ & $\mathbf{4 5}^{\circ}$ & $\mathbf{6 0}^{\circ}$ & $\mathbf{7 5}^{\circ}$ & $\mathbf{9 0}^{\circ}$ \\
\hline $\mathrm{K}_{1}$ & 1.33 & 1.4 & 1.65 & 1.9 & 2.75 & 2.72 & 1.83 \\
\hline
\end{tabular}

Table 4. The transverse anisotropy parameters

\begin{tabular}{lllll}
\hline $\mathbf{E} / \mathbf{G P a E}^{\prime} / \mathbf{G P a}$ & $\mathbf{v}$ & $\mathbf{v}^{\prime}$ & $\mathbf{G} / \mathbf{G P a}$ \\
\hline 11.32 & 17.1 & 0.380 .39 & 6.15 \\
\hline
\end{tabular}

\subsection{Influence of bedding angle}

The previous research [18] shows that the change law of uniaxial compressive strength is closely related to the bedding angle, and the angle between different layers bears on the failure mode of the schist [18].

Figure 7 presents the variations in the uniaxial compressive strengths, elastic moduli, and Poisson's ratios of strongly and weakly weathered dry samples with bedding angle. When the bedding angle was $0^{\circ}$, the uniaxial compressive strength and elastic modulus were high, while the Poisson's ratio was small. 
As the bedding angle increased to $15^{\circ}$ and $30^{\circ}$, the uniaxial compressive strength and elastic modulus steadily decreased, while the Poisson's ratio slightly increased. As the bedding angle increased to $45^{\circ}$ and $60^{\circ}$, the uniaxial compressive strength and elastic modulus were minimized, while the Poisson's ratio slightly increased. As the bedding angle increased to $75^{\circ}$ and $90^{\circ}$, the uniaxial compressive strength and elastic modulus rebounded significantly, while the Poisson's ratio declined.

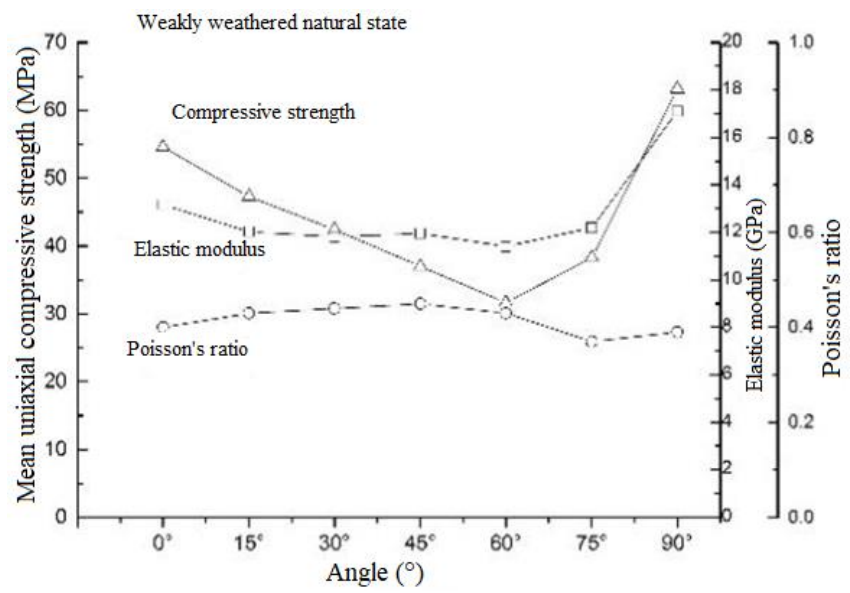

(a) Uniaxial compressive strength, elastic modulus, and Poisson's ratio of weakly weathered dry samples

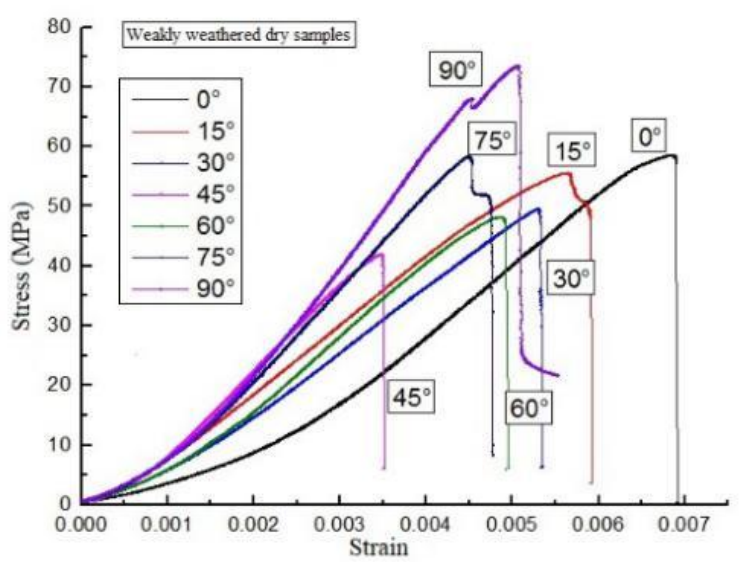

(b) Stress-strain curves of weakly weathered dry samples

Figure 7. The influence of bedding angle

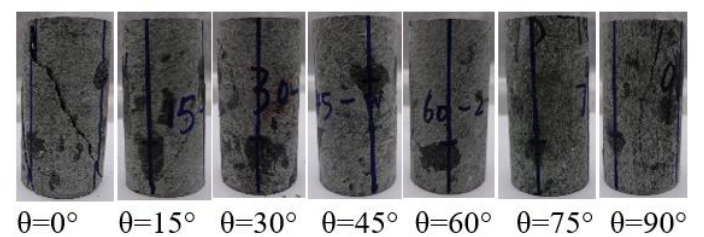

Figure 8. The examples of uniaxial compressive failures

As shown in Figure 8, the samples with different schistose structures experienced three main failure modes. The sample with $\theta=0^{\circ}-15^{\circ}$ suffered tensile and shear failures along the bedding plane. Multiple parallel cracks gradually appeared on the fracture surface, causing the stress-strain curve to oscillate about the peak value. Moreover, large fractures appeared at the edges and ends of the failed sample. Fragments were observed on the uneven fracture surfaces. The overall failure mode is the shear failure of local matrix.
In the sample with $\theta=30^{\circ}-60^{\circ}$, the main crack propagated on a smooth fracture surface along the bedding direction. The damaged surface was smooth and flat. This is the result of the development of the fracture surface along the edges of the directional mineral flakes. The overall failure mode is the shear slip failure along the bedding surface.

In the sample with $\theta=75^{\circ}-90^{\circ}$, the main crack developed vertically downward along the schistosity, and penetrated the two ends of the sample. A few secondary cracks appeared nearby, causing the stress-strain curve to fluctuate before and after the peak. The fracture surface was very prominent, and large fractures emerged on the edges. The overall failure mode is the shear failure of local matrix.

\subsection{Water softening effect}

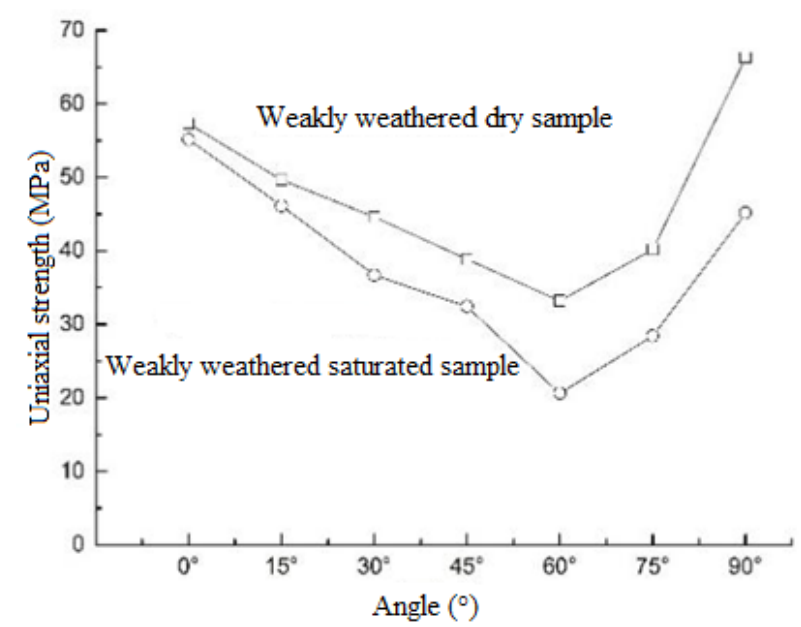

(a) Mean uniaxial strengths of saturated and dry samples

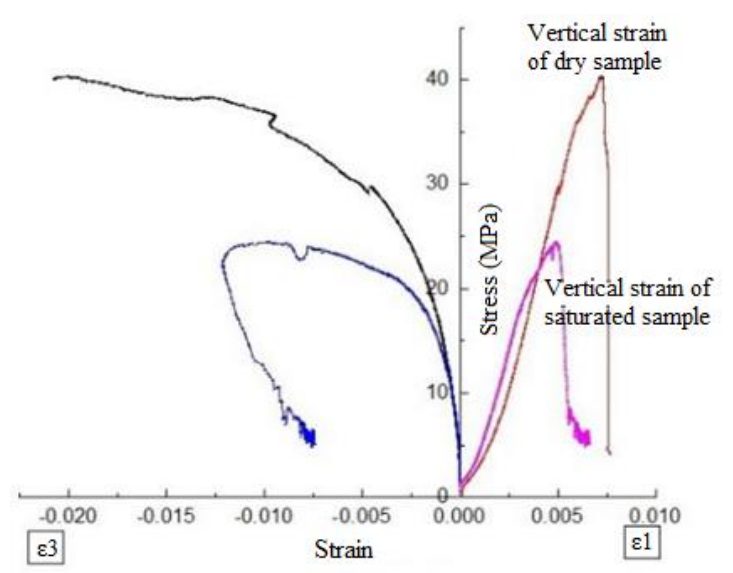

(b) Stress-strain curves of dry and saturated samples

Figure 9. The water softening effect

Chlorite schist is a typical soft rock with schistose structure. In engineering applications, the rock is affected by many factors, such as precipitation, surface water infiltration, groundwater, overburden thickness, air humidity, and temperature. The water softening property of this rock is bound to reduce the strength of the engineering rock mass. To clarify its softening effect, the saturated chlorite schist samples were subject to uniaxial compression test.

Figure 9 compares the strength distributions of dry samples and saturated samples. It can be seen that the dry samples had a greater strength than the saturated samples. Take the samples with the bedding angle of $45^{\circ}$ for instance. The strength of the saturated sample averaged at $32.42 \mathrm{MPa}$, while that of the dry 
sample averaged at $37.01 \mathrm{MPa}$. The ratio of saturated strength to dry strength was about $0.8-0.82$, and the softening effect coefficient of chlorite schist stood at 0.5 .

As shown in Figure 9(b), after the peak of the stress-strain curve, the axial stress entered the decline, but the lateral strain continued to increase. Thus, the bearing capacity of the sample plunged, and the strain energy was released quickly. To sum up, the strength of the saturated sample was about $0.8-0.82$ times that of the dry sample, indicating a prominent softening effect. However, the effect of the bedding angle on the strength remains basically unchanged whether the sample is saturated or dry.

\subsection{Weathering effect}

The deformation and instability of strongly weathered rocks are commonplace in shallow tunnels. In Section 2, the mineral compositions of weakly and strongly weathered chlorite schists are compared through XRD. The results show that redox reaction occurs between weakly weathered chlorite schist and the air, leading to the loss of some chemical elements. The ensuing changes of mineral particles induce pores alter the mechanical properties of the rock.

To clarify the weathering effect of chlorite schist, the weakly and strongly weathered samples were compared through uniaxial compression test. As shown in Figure 10, the weakly weathered sample had much greater compressive strength than the strongly weathered sample: the mean compressive strength of weakly weathered sample was $46.38 \mathrm{MPa}$, while that of strongly weathered sample was only $12.83 \mathrm{MPa}$. The strength ratio of strongly weathered state to weakly weathered state fell between 0.2 and 0.3 , that is, the strength of strongly weathered sample was only 0.2-0.3 times of that of weakly weathered sample. However, the strengths of both samples changed similarly with the bedding angle.

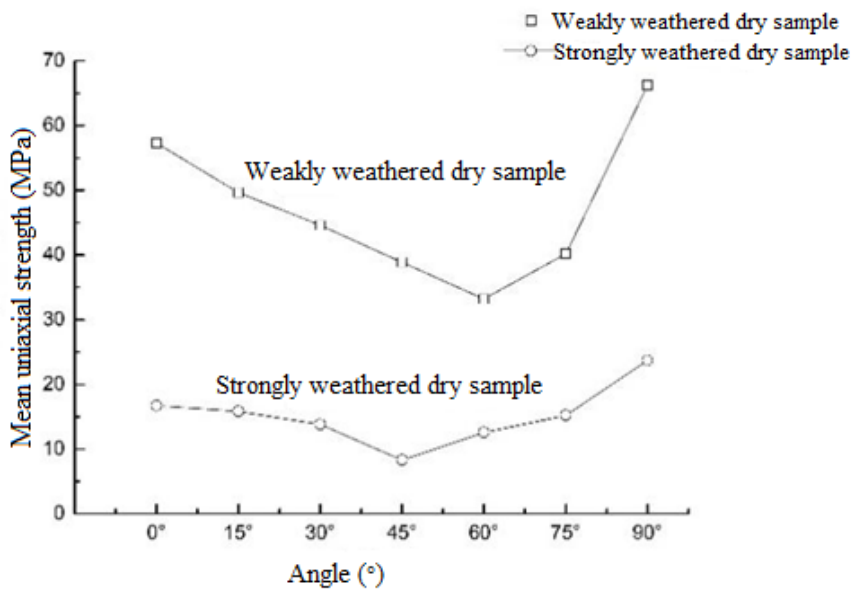

Figure 10. The weathering effect

\section{CONCLUSIONS}

This paper carries out indoor uniaxial compressive tests on chlorite schists, and discusses how schistose structure, water softening effect, and weathering effect influence the rock strength. The main conclusions are as follows:

(1) Comparing the mineral compositions of weakly and strongly weathered chlorite schists, redox reaction occurs between weakly weathered chlorite schist and the air, leading to the loss of some chemical elements. The ensuing changes of mineral particles induce pores alter the mechanical properties of the rock.

(2) Chlorite schist is a low-anisotropy rock mass. With the growing bedding angle, the uniaxial compressive strength of samples exhibited a V-shape trend: the strength decreased first and then increased. This proves the influence of schistose structure on the rock damage.

(3) The mechanical parameters of dry chlorite schists were higher than those of saturated chlorite schists and those of strongly weathered chlorite schists, indicating that chlorite schist is prone to water softening and weathering. In addition, the influence of bedding angle on sample strength remained the same, despite the change of sample state. This means schistose structure is the internal cause of the anisotropic damage of chlorite schist, which is further damaged under external factors (e.g. the water softening and weathering effects) in engineering.

(4) Three failure modes were observed on chlorite schists through uniaxial compression tests. The sample with $\theta=0^{\circ}-15^{\circ}$ suffered the shear failure of local matrix; the sample with $\theta=30^{\circ}-60^{\circ}$ suffered the shear slip failure along the bedding surface; the sample with $\theta=75^{\circ}-90^{\circ}$ suffered the shear failure of local matrix.

\section{REFERENCES}

[1] Zong, Z. (2017). Transverse isotropic mechanical properties and constitutive model of slate. Shandong University.

[2] Avchar, A., Choudhary, B.S., Budi, G., Sawaiker, U.G. (2018). Effect of rock properties on rippability of laterite in Iron Ore mines of Goa. Mathematical Modelling of Engineering Problems, 5(2): 108-115. https://doi.org/10.18280/mmep.050208

[3] Manthei, G. (2005). Characterization of acoustic emission sources in a rock salt specimen under triaxial compression. Bulletin of the Seismological Society of America, 95(5): 1674-1700. https://doi.org/10.1785/0120040076

[4] Alkan, H., Cinar, Y., Pusch, G. (2007). Rock salt dilatancy boundary from combined acoustic emission and triaxial compression tests. International Journal of Rock Mechanics \& Mining Sciences, 44(1): 108-119. https://doi.org/10.1016/j.ijrmms.2006.05.003

[5] Li, Z.G. (2017). Generating relations between geological disaster and engineering properties of metamorphic rocks in Duhe river basin. China University of Geosciences.

[6] Gautam, R., Wong, R. C. (2006). Transversely isotropic stiffness parameters and their measurement in Colorado shale. Canadian Geotechnical Journal, 43(12): 12901305. https://doi.org/10.1139/t06-083

[7] Read, S.A.L., Perrin, N.D., Brown, I.R. (1987). Measurement and analysis of laboratory strength and deformability characteristics of schistose rock. In 6th ISRM Congress. International Society for Rock Mechanics and Rock Engineering, 233-238.

[8] Li, J.T., Wang, H.W., Lin, H. (2016). Relationship among stratification angle, compressive strength, and fracture toughness of transversely isotropic slate. Journal of Hunan University (Natural Science Edition), 43(7): 126-131. 2974.2016.07.017 
[9] Liu, S.L., Chen, S.X., Yu, F., Zhao, W.G. (2012). Anisotropic properties study of chlorite schist. Geotechnical Mechanics, 33(12): 3616-3623.

[10] Zhou, H., Yang, X., Hu, Q.Z., Cheng, C.B. (2011). Study on the strength test and mechanism of chlorite schist softening in contact with water. Soil Engineering and Foundation, $\quad 25(1)$ : $\quad 45-48, \quad 69$. https://doi.org/10.3969/j.issn.1004-3152.2011.01.014

[11] Liu, N., Zhang, C.Q., Chu, W.J., Zhu, H.C., Zhang, W., Zhang, Y. (2013). Deformation behavior and stability analysis of deep chlorite schist. Journal of Rock Mechanics and Engineering, 32(10): 2045-2052.

[12] Liu, J., Wang, L., Li, J.L., Yuan, T.F., Yan, L.Z. (2017). Experimental study on isotropic strength parameters of quartz-mica schist. Chinese Journal of Rock Mechanics and Engineering, 36(S2): 3740-3751.

[13] Wu, F.B. (2019). Experimental study on mechanical characteristics of mica quartz schist foliation surface. Chinese Journal of Geotechnical Engineering, 41(S1):
117-120. https://doi.org/10.11779/CJGE2019S1030

[14] Sun, T., Yang, Y.N., Gao, S.F., Liu, J., Xie, XK., Han, S.K. (2019). Research on stability of schist tunnel based on transversely isotropic model. Journal of Water Resources and Water Engineering, 30(5): 221-229.

[15] Brown, E.T., Hoek, E. (1980). Underground excavations in rock. Institute of Mining and Metallurgy, 19(3): 244246.

[16] Heng, S., Yang, C.H., Zhang, B.P., Guo, Y.T., Wang, L., Wei, Y.L. (2015). Experimental study on anisotropy properties of shale. Rock and Soil Mechanics, 36(3): 609-616. https://doi.org/10.16285/j.rsm.2015.03.001

[17] Singh, J., Ramamurthy, T., Venkatappa Rao, G. (1989). Strength anisotropies in rocks. Indian Geotechnical Journal, 19(2): 147-166.

[18] Mu, J.F. (2016). Exploration of the anisotropic mechanical of shale. Unconventional Oil \& Gas, 2016(5): 39-40. 